BULLETIN Bulletin hispanique

HISPANIQUE Université Michel de Montaigne Bordeaux

118-1 | 2016

La Guerre Civile espagnole aujourd'hui (1936-2016)

\title{
La reacción internacional
}

el caso de Francia y la Sociedad de Naciones

David Jorge

\section{(2) OpenEdition}

Journals

Edición electrónica

URL: http://journals.openedition.org/bulletinhispanique/4236

DOI: 10.4000/bulletinhispanique.4236

ISSN: 1775-3821

Editor

Presses universitaires de Bordeaux

Edición impresa

Fecha de publicación: 15 julio 2016

Paginación: 83-98

ISBN: 979-10-300-0058-0

ISSN: 0007-4640

Referencia electrónica

David Jorge, « La reacción internacional », Bulletin hispanique [En línea], 118-1 | 2016, Publicado el 15

julio 2019, consultado el 07 septiembre 2019. URL : http://journals.openedition.org/

bulletinhispanique/4236 ; DOI : 10.4000/bulletinhispanique.4236 


\title{
La reacción internacional: el caso de Francia y la Sociedad de Naciones
}

\author{
DAvid Jorge \\ Instituto de Investigaciones Históricas - UNAM - México ${ }^{1}$
}

L'article parcourt la politique extérieure française des années 1935-39 à travers ses manifestations à la Société des Nations : des principes éthiques de l'opposition jusqu'à son pragmatisme politique une fois au pouvoir ; de ses réactions timorées et égoïstes jusqu'à l'abandon de la démocratie espagnole; de la non-intervention et de l'adhésion à l'appeasement britannique jusqu'à l'autodestruction du Front Populaire, la débâcle et l'instauration du régime de Vichy.

Mots-clés : Front populaire, Appeasement, Société des Nations, Guerre d'Espagne, Décadence.

El artículo recorre la política exterior francesa de los años 1935-39, a través de su reflejo en la Sociedad de Naciones : desde los principios éticos de la oposición a un pragmatismo político una vez al poder ; desde los miedos y egoísmos al abandono de la democracia española ; desde la no intervención y el seguidismo al appeasement británico a la autodestrucción del Front Populaire, al abandono de responsabilidades, a la derrota y al régimen de Vichy.

Palabras claves: Front populaire, Appeasement, Sociedad de Naciones, Guerra de Espańa, Décadence.

The article runs through the French foreign policy in the years 1935-39, through its manifestations in the League of Nations: from the ethical principles of the opposition, to its political pragmatism once in office; from its timorous and selfish reactions to the abandonment of Spanish democracy; from the non-intervention and adherence to the British appeasement to the self destruction of the Popular Front, the debacle and establishment of the Vichy regime.

Keywords: Front Populaire, Appeasement, League of Nations, Spanish Civil War, Décadence.

1. El autor ha realizado el presente trabajo en calidad de beneficiario del Programa de Becas Posdoctorales de la UNAM (Universidad Nacional Autónoma de México), integrado en el Instituto de Investigaciones Históricas.

Bulletin Hispanique, Tome 118, n 1 - juin 2016 - p. 83-98. 
Principios EN LA OPOSICIÓN, PRAGMATISMO EN EL GOBIERNO: EL FRONT POPULAIRE

Cuando en diciembre de 1935 se conoció el Acuerdo Hoare-Laval, consistente en un plan de partición de Etiopía con el fin de conceder a la Italia de Benito Mussolini -que había agredido al Estado independiente africano- la soberanía sobre una parte fundamental del país, el dirigente del Partido Radical francés, Yvon Delbos, arremetió en discurso parlamentario contra el primer ministro de su país. Le acusó de no orientar la política exterior de acuerdo al Pacto de la Sociedad de Naciones y el sistema de seguridad colectiva, doctrina mantenida desde el final de la Gran Guerra de 1914-1918. Tras glosar el ejemplo de su compatriota Aristide Briand en base a su apuesta por el multilateralismo ginebrino, declaró: «No se puede alentar al agresor, sacrificándole su víctima. Es nuestra seguridad la que está en juego. [...] Al destruir la seguridad colectiva, destruiríamos nuestra propia seguridad $»^{2}$.

Efectivamente, cuando la coalición de Front Populaire obtuvo la victoria en las elecciones generales celebradas en mayo de 1936, lo hizo con un programa electoral que incluía un apartado denominado Défense de la Paix, compuesto por siete apartados de los cuales tres (los números 2, 5 y 6) estaban referidos a la Sociedad de Naciones, estipulando lo que sigue:

- Colaboración internacional, en el marco de Ginebra, por la seguridad colectiva, de cara a definir al agresor y la aplicación automática y solidaria de sanciones en caso de agresión.

- Repudio a la diplomacia secreta, acción internacional y negociaciones públicas para volver a llevar a la Sociedad de Naciones a los Estados apartados de Ginebra, sin atentar contra los principios constituyentes del organismo: seguridad colectiva y paz individual.

- Flexibilización del procedimiento previsto por el Pacto de la Sociedad de Naciones para el ajuste de los tratados peligrosos para la seguridad del mundo ${ }^{3}$.

Tras la formación del nuevo gobierno frentepopulista en París, todo el idealismo multilateral dio paso inmediato, una vez alcanzado el poder, a un pragmatismo total: a principios de julio de 1936, Francia votó a favor del levantamiento de las sanciones impuestas contra Italia en la Sociedad de Naciones por su agresión a Etiopía. La Asamblea de la Sociedad de Naciones estipuló tal supresión, bajo claro impulso británico. La impunidad se había instalado. Mussolini y Hitler lo percibieron muy nítidamente.

2. Diario $A B C$ (Madrid). Edición del 28 de diciembre de 1935, p. 27.

3. Jules Moch, Le Front Populaire, grande espérance..., Paris, Librairie Académique Perrin, 1971, pp. 227-228. 


\section{El QUAI D'ORSAY TOMa La INICIATIVA ANTE LOS Miedos DE BLUM EN UN PAÍs DIVIDIDO}

La división tanto del gobierno como de la sociedad francesa fue un hecho a partir del golpe de Estado producido en Espańa en julio de 1936. Tal división distaba de ser homogénea, tal y como ha explicado Bonnefous: «Hubo en la izquierda hombres que, queriendo ante todo salvaguardar la paz europea, guardaron silencio. La política de no intervención gubernamental fue inspirada por ellos. Igualmente, algunos hombres de derechas no aplaudieron incondicionalmente los hechos y gestas del general Franco. Los católicos, en especial, se hicieron muchas preguntas». Un caso muy representativo fue el de François Mauriac, quien tras haber rogado al primer ministro, Léon Blum, que no interviniese a favor de la República, cambió de postura a partir del mes de agosto, posicionándose contra los sublevados en España ${ }^{4}$. Pero Blum, incapacitado por sus temores para ejercer con determinación su autoridad, se limitó a derramar lágrimas de cocodrilo sobre los hombros de los interlocutores del gobierno español que le visitaban en su domicilio del número 25 del Quai de Bourbon, como Fernando de los Ríos o Luis Jiménez de Asúa. Dicha actitud de Blum posibilitó que el Quai d'Orsay tomase las riendas de la actitud a adoptar en relación a la situación en España. La puesta en pie de la política de no intervención -bajo patrocinio francés y claro impulso británico- se constituyó a partir de aquel entonces como hecho irreversible para toda la contienda. Fue ahí donde la firmeza en la sombra de Alexis Léger, hombre fuerte del ministerio y partidario de un decidido seguidismo a la diplomacia británica, se combinó con una puesta en escena también al margen de dudas por parte del ministro de Asuntos Exteriores, Yvon Delbos. Este, en el primer encuentro de la Sociedad de Naciones tras el estallido de la contienda, respondió a las denuncias del ministro español, Julio Álvarez del Vayo, reafirmando la no intervención como medio para «impedir la movilización ideológica de Europa»". Eso era lo fundamental para los arquitectos de la política exterior gala, en tanto que Blum seguía bloqueado. El mencionado Léger se lo dejó claro al embajador italiano en París, Mario Cerruti: lo mejor que podía pasar era que el asunto español terminase cuanto antes, con independencia de quién obtuviese la victoria ${ }^{6}$.

Entre julio y noviembre de 1936 se consolidó la configuración internacional de la Guerra de España, con su balanza de acciones y retracciones. Fue en dicho período en el que también se plasmó el abandono de la seguridad colectiva (en base a la anteposición del secretismo del Comité de No Intervención al

4. Édouard Bonnefous, Histoire politique de la troisième République. IV, Paris, Presses Universitaires de France, 1965, p. 43.

5. Ricardo Miralles, «El duro forcejeo de la diplomacia española en París», en Ángel Viñas (dir.), Al servicio de la República: Diplomáticos y guerra civil, Madrid, Marcial Pons, 2010, p. 127.

6. Ángel Viñas, La República en guerra: Contra Franco, Hitler, Mussolini y la hostilidad británica, Barcelona, Crítica, 2012, p. 95. 
multilateralismo de la Sociedad de Naciones) y del compromiso con el Derecho Internacional (tras los antecedentes de Manchuria, Abisinia y Renania), en pro de un apaciguamiento general que situaba a Francia en primera línea de posible agresión, y de una no intervención para el caso español que en la práctica no representó sino una intervención de facto contra la República.

\section{MÉXICO: El EJEMPLO NO SEGUIDO}

El primer día de agosto de 1936, Delbos justificaba la retracción francesa de la siguiente manera: «Habríamos podido enviar armas al gobierno español, gobierno legítimo en derecho y de hecho. No lo hemos hecho, ante todo por doctrina y humanidad, y para no dar pretextos a los que se sientan tentados a suministrárselas a los rebeldes». Dos días más tarde, el embajador mexicano en París, Adalberto Tejeda, dirigió una petición a Delbos informando el interés de su gobierno de adquirir material de guerra (entre el cual se incluían aviones caza, bombarderos y bombas de aviación). El titular del Quai d'Orsay rechazó la solicitud justificando la negativa en las propias necesidades bélicas del país galo, por lo que se excusó diplomáticamente. Sin embargo, la verdad no residía en aquella misiva de respuesta de Delbos, sino en la que este dirigió aquel mismo día al ministro del Aire, Pierre Cot, y en la que afirmaba que "por razones políticas no había lugar a satisfacer esta demanda ${ }^{7}$.

Ocho meses después, el embajador volvería a dirigirse al ministro, insistiendo en la línea seguida por su compatriota Fabela ante la Sociedad de Naciones, quien lamentó que determinadas actuaciones por parte de «los cultos gobiernos europeos [...] no parecen armonizar con las obligaciones que impone el Pacto [y que] la no intervención seguida por algunos Estados en el caso actual no es, en último análisis, sino una ayuda indirecta y no por eso menos efectiva a favor de los rebeldes» ${ }^{8}$. Añadió Tejeda que comprendía los deseos de que el conflicto no se extendiese más allá de las fronteras españolas, pero que el trato dado al Gobierno de la República no hacía sino prolongar cruelmente la contienda. Por ello, México apelaba «a los sentimientos humanitarios» del país galo, «universalmente reconocidos [...] para que se esfuerce en encontrar la vía amistosa que ponga fin a la situación dolorosa que atraviesa España'».

México, al contrario que Francia, no se autoengañó en cuanto al quid de la cuestión española: se trataba de una guerra internacional, lo que conllevaba la necesidad de aplicación del Derecho Internacional, empezando por el Pacto de la Sociedad de Naciones. México se pronunció con claridad en Ginebra, al contrario que una diplomacia franco-británica que prefirió la privacidad que

7. Ministère des Affaires Étrangères -Direction des Affaires Politiques et CommercialesSous-direction d'Amérique. Mexique. Carp. 40. 13-08-1936. Información facilitada al autor por Miguel I. Campos, quien profundizará sobre el asunto en su próxima tesis doctoral.

8. Ángel Viñas, El escudo de la República: El oro de España, la apuesta soviética y los hechos de mayo de 1937, Barcelona, Crítica, 2007, p. 225.

9. Ministère des Affaires Étrangères - AD - SDN (La Courneuve, Paris) - 2049. 
proporcionaba el Comité de No Intervención para la adopción de decisiones poco defendibles o justificables, legal y éticamente.

\section{Moscú: LA ALTERNATIVA NO ADOPTADA}

Si bien adoptar la postura ética y legalista de México ante la Guerra de España podría parecer una utopía dado el contexto en que se desenvolvía la Francia de los años treinta, París sí contaba con otra carta para hacer contrapeso en el equilibrio de fuerzas internacional. Pese a que el aliado lógico de la democracia gala no debía ser otro que el régimen homólogo de Londres - con todos los matices que se quiera en cuanto al diferente carácter de ambos gobiernos-, ello no significa que la única potencia a la que el ejecutivo francés pudiese aferrarse la constituyesen los británicos.

En el mes de mayo de 1935 se había firmado el Pacto Franco-Soviético de asistencia mutua en caso de agresión proveniente del exterior. En diciembre de aquel mismo año, París y Madrid firmaron asimismo un tratado comercial, añadiéndose al mismo un affidavit tras la victoria electoral del Front Populaire en mayo de 1936, en virtud del cual el gobierno español -en representación del cual firmaba el ministro de Estado, Augusto Barcia- se comprometía a comprar material de guerra a Francia, sobre todo de aviación, por valor de 40 millones de francos ${ }^{10}$. El contexto en el cual se enmarcaban tales acuerdos evidencia las motivaciones de los mismos: a la incómoda vecindad de la Italia fascista desde más de una década atrás en el tiempo, tras la llegada de Adolf Hitler al poder había que ańadir una nueva frontera compartida con la Alemania nazi. Francia siguió basando su confianza en materia de seguridad en Londres, si bien pareció entender la necesidad de abrir más puertas.

La mencionada llegada al poder de la coalición del Front Populaire, precedida del triunfo de una coalición también frentepopulista en España apenas tres meses antes, parecía reforzar las alternativas diplomáticas a Gran Bretaña, a cuyo gobierno conservador resulta evidente que no gustaba en absoluto la deriva izquierdista en Francia y Espańa. Si hasta entonces la diplomacia francobritánica, ignorando el multilateralismo y el respeto al Pacto de la Sociedad de Naciones, había pasado a entenderse a nivel bilateral (llegando a su cénit con el Pacto Laval-Hoare), recobrando las prácticas de la vieja diplomacia -aquella anterior a la Gran Guerra de 1914-1918-, el nuevo escenario político en París y Madrid alteró las prioridades del Foreign Office. Incluso cuando se hizo evidente que Francia no saltaría en socorro de su vecino del sur, incumpliendo no sólo el Derecho Internacional, sino también los acuerdos particulares entre ambos países, como fue el caso del mencionado contrato de diciembre de 1935 y su affidavit de seis meses después. La búsqueda de la división entre Hitler y Mussolini, fundamentalmente en base a la atracción del segundo hacia campo

10. Augusto Barcia, Un golpe de Estado internacional (La politica de no intervención), Buenos Aires, PHAC, 1944, p. 23. 
propio, marcó la política exterior británica hasta el momento mismo de la invasión de Polonia y la declaración formal de guerra, en septiembre de 1939. Sólo entonces entendió Londres que el Eje era una realidad indisoluble. El que fuera poderoso responsable del Foreign Office, Anthony Eden, lo comprendió un poco antes, y pasó a obrar en consecuencia. Le costó su salida del gobierno.

Para entonces, Francia seguía sin valorar la otra única posible alianza con una potencia susceptible de alejar su mayor temor: verse desamparada y débil en el continente europeo. El soviético Maxim Litvinov, comisario del pueblo para Asuntos Exteriores, apeló ante la Sociedad de Naciones en septiembre de 1936 al "país amigo", recordando a Francia su alianza y tratando de reorientar la postura gala hacia la República Española. Sin embargo, siempre pesó más en París la amenaza del embajador británico, sir George Clerk, a Delbos el 7 de agosto anterior: en caso de intervención en España, el gobierno británico se desentendería si en un futuro Alemania agredía a Francia. «Tengo razones para creer que los extremistas del gobierno [francés] estuvieron ejerciendo una creciente presión en el señor Blum, y estoy seguro de que lo que dije puede reforzar las manos de los elementos moderados y sobrios», transmitió Clerk a sus superiores ${ }^{11}$. Dicha gestión -autónoma en su origen, pero pronto ratificada y respaldada por el propio Foreign Office- fue clave. A partir de ahí, París se hizo pequeño.

\section{Dudas, alarmas y VÉrtigo: El amago de Viraje del Gobierno Chautemps}

En el verano de 1937, el no funcionamiento de la no intervención era un hecho innegable. Con motivo de la ceremonia de apertura del Pabellón de la Paz, en el marco de la Exposición Universal celebrada en París, Delbos reconoció a la duquesa de Atholl -diputada conservadora británica que, sin embargo, luchó por la causa de la República y denunció abiertamente tanto la política de no intervención como la inhibición de la Sociedad de Naciones- su escepticismo hacia el papel del organismo ginebrino en el convulso panorama internacional, si bien matizó que todavía podía servir para retirar a los combatientes no españoles del conflicto, y que la primera advertencia para Roma y Berlín debía consistir en la apertura de la frontera franco-española ${ }^{12}$. No se trató de un farol: era el inicio del período en el que más cerca estuvo París de un cambio de dirección en su política internacional. Francia, cada vez más sola ante las iniciativas particulares británicas y, sobre todo, alertada por los intentos de entendimiento de Londres con Roma, pasó a reconsiderar su papel en la esfera internacional.

11. Anthony R. Peters, Anthony Eden at the Foreign Office, 1931-1938, Aldershot, Gower, 1986, pp. 229-230.

12. The National Archives (London) - FO 371/21343 - 111-116. 
Que tal cambio de orientación francesa no contemplaba la vía de Ginebra para canalizarlo resulta claro. El mismo Delbos comentó al delegado chino, Wellington Koo, que era lo mismo pedir ayuda a la Luna que a la Sociedad de Naciones ${ }^{13}$. De hecho, la diplomacia franco-británica, no contenta con la desviación que representaba el Comité de No Intervención establecido en Londres, optó por desvirtuar todavía más el ámbito multilateral al convocar la Conferencia de Nyon, bajo la intención de reducir las tensiones en el Mediterráneo -que tanto alertaban en París, dada la agresividad italiana y la aquiescencia británica-. Para ello se invitó a Nyon a todos los países mediterráneos, a excepción de Espańa. Todo un nuevo detalle para con la democracia vecina. En dicha ocasión, los británicos arrastraron nuevamente a Francia fuera del ámbito de la Sociedad de Naciones dorando la píldora a Delbos, a quien Eden ofreció la presidencia de la conferencia.

Sin embargo, sí fue en Ginebra donde se acentuó la nueva postura del Gobierno Chautemps. Ello tuvo lugar por la influencia del inmaculado discurso del presidente del gobierno español, Juan Negrín, el 18 de septiembre de 1937 ante la Asamblea de la Sociedad de Naciones. Si ya no era habitual que un primer ministro se personase en Ginebra, la personalidad de Negrín marcó un especial contraste con el tono grisáceo predominante en el Palais des Nations. El gobierno francés percibió más nítidamente que nunca que, más allá de persuasión y retórica, las advertencias españolas tenían un componente real internacional, el cual amenazaba en primer lugar a la propia Francia. Los esfuerzos diplomáticos españoles se habían redirigido de las orillas del Támesis a las del Sena. Las palabras de Negrín -y de Álvarez del Vayo- se unían al arrodillamiento británico ante el albedrío de Mussolini. Roma había adelantado a París en el orden de prioridad de los esfuerzos de persuasión londinenses. Ello tuvo efectos. No obstante, el vértigo ante una completa soledad, en caso de abandono de cualquier compromiso de auxilio por parte británica, hizo que la determinación francesa no llegase al punto de aliarse activamente con la causa republicana española. El espectro del embajador Clerk persistía.

La consecuencia del cambio de percepción por parte gala resultó en la apertura de la frontera pirenaica con el fin de permitir el paso de material de guerra destinado a la República. Sin embargo, tal decisión coindició con la pérdida de interés soviético en la Guerra de España con motivo del estallido de la Segunda Guerra Sino-Japonesa en aquel verano de 1937. Ello significó una reducción drástica de los envíos destinados al gobierno español desde Moscú.

A finales de octubre el gobierno británico debatió sobre la cuestión española, reafirmándose el interés en lograr la retirada de todos los combatientes no españoles presentes en ambos bandos. Tal interés perseguía un claro objetivo: reducir la evidente significación internacional de la contienda -prioridad absoluta tanto en Londres como en París durante toda la Guerra de Espańa- y, sobre todo, calmar los ánimos franceses. Los representantes galos habían pasado 
a denunciar continuamente la actitud de Italia ante sus colegas británicos; y, en particular, la presencia de verdaderos cuerpos de ejército transalpinos al otro lado de los Pirineos. El embajador francés en Londres, Charles Corbin, fue más lejos y afirmó que no bastaba con la mera aquiescencia por parte británica en la apertura de la frontera, sino que era también necesaria alguna acción en positivo. De no ser así, la dinámica de los acontecimientos podía derivar en una situación muy grave en el continente europeo. Y, de hecho, en el último encuentro de la Sociedad de Naciones los países mediterráneos habían mostrado su intención de pasar a una mayor firmeza si Mussolini no cambiaba su actitud, e incluso reconsiderar la existencia de la política de no intervención. Poco después, Francia presionaría para que, en caso de fracasar las negociaciones del Comité de No Intervención para restar dicho componente internacional a la cuestión española, ambos países procediesen a la venta de armamento al Gobierno de la República. Chamberlain comentó a sus ministros que «desde un punto de vista político no sería posible diferenciar entre el gobierno [español] y el general Franco", por lo que tal venta de armamento debería producirse en igualdad de condiciones para ambos contendientes. E insistió en un aspecto clave para Londres desde el mismo inicio de la contienda en Espańa: lograr que «se convirtiese en una guerra civil española y no en una guerra extranjera $»^{14}$. Es decir, reconocía implícitamente el premier británico el quid de la cuestión: que la de España no era una mera guerra civil, sino una contienda internacional en toda regla.

Para entonces, Eden había pasado a asumir que, ante la constatación clara de una guerra internacional en Espańa, había que mostrar una mayor firmeza. Tal postura resultaba incompatible con el apaciguamiento sin límites de Chamberlain. La relación entre ambos se había ido deteriorando rápidamente (con puenteos al otrora poderoso Eden incluidos, como el envío de lord Halifax a Berchtesgaden para entrevistarse con Hitler, a espaldas del secretario del Foreign Office). El punto de no retorno llegó en el mes de diciembre, con motivo del incremento de la presencia y actividad italiana en Mallorca. Eden propuso entonces convocar a Blum en Londres, a lo que se opuso la gran mayoría de ministros, los cuales apostaron por el refuerzo del appeasement, con Chamberlain y sir Samuel Hoare a la cabeza. Por otro lado, las conversaciones entre Londres y Roma motivaron en Francia un claro sentimiento de marginación y abandono. Para colmo, Italia se situó en todo momento en una posición de superioridad en las negociaciones. Eden comprendió entonces que negociar con Mussolini no tenía valor alguno, y que la cuestión española era, y seguiría siendo, una guerra internacional. Seguir aceptando los chantajes italianos era inaceptable y no podía conducir a nada bueno. Así se lo planteó al primer ministro y afirmó en reunión ministerial que, en caso de querer continuar con la misma política exterior, no tendría otra alternativa que redactar su carta de dimisón. Chamberlain aceptó la renuncia y Eden abandonó el consejo de 
ministros, al igual que su subsecretario, lord Cranborne ${ }^{15}$. El camino quedaba expedito para Chamberlain, quien contaba para sus planes de política exterior con hilo directo hacia Mussolini a través de la viuda de su hermanastro Auden, quien urgía con insistencia a negociar con Italia ${ }^{16}$. La salida de Eden constituyó el punto de partida para que la no intervención aplicada a España derivase en la reaparición del appeasement, que no era sino el mismo tipo de política pero aplicada a escala general, y no solamente para el caso espańol.

Francia iniciaba, pues, el año 1938 abandonada por su principal apuesta como alianza defensiva ante el cada vez más que posible rodeo total por regímenes fascistas: a Hitler y a Mussolini parecía que se les sumaría en breve, si el rumbo internacional no cambiaba radicalmente, el general Franco. En medio de tal panorama, Negrín se trasladó a París con el fin de tratar personalmente ante los ministros franceses las posibilidades de ayuda. Tras el cambio de actitud del Gobierno Chautemps durante el verano y otońo anterior, el gobierno español albergaba razones de peso para sońar con una Francia más comprometida con su democracia vecina. En tal contexto, y con el presidente español en París, tuvo lugar en la capital gala un nuevo cambio de gobierno: Blum regresaba como primer ministro y, quizás más importante todavía, Joseph Paul-Boncour pasaba a hacerse cargo del Quai d'Orsay. La política exterior gala pasaría a pivotar, pues, sobre otros soportes diferentes. Cabe señalar que Paul-Boncour se había opuesto en su momento a la puesta en pie de la no intervención, y no se trataba de alguien sospechoso de radicalismo alguno, como muestra su afirmación en enero de 1937 ante Cipriano Rivas Cherif, entonces cónsul español en Ginebra, de que «a ningún gobierno francés le gustaría ni poco ni mucho la posibilidad próxima o remota de una frontera comunista en Perpignan ${ }^{17}$. Sencillamente, no se dejaba obnubilar por miedos y egoísmos en su interpretación de la deriva internacional. Además, era el jefe de la delegación francesa ante la Sociedad de Naciones, por lo que era previsible su apuesta por el marco multilateral como vía alternativa a un secretismo como el del Comité de Londres, que se estaba revelando como pernicioso para los intereses galos. Es bastante probable, pues, que su nombramiento obedeciese a dicha lógica, derivada de las nuevas percepciones surgidas con el Gobierno Chautemps. El nuevo ministro representaba para la República una importante esperanza. Con Delbos, y tras él siempre el influyente Alexis Léger ${ }^{18}$, la no intervención jamás pudo alterarse. La hostilidad de ambos hacia la República se hizo evidente desde el primer momento. Delbos no sólo impidió el paso de material de

15. The National Archives (London) - CAB/23/92 - 248 .

16. Ian Kershaw, Un amigo de Hitler: Inglaterra y Alemania antes de la Segunda Guerra Mundial, Barcelona, Península, 2013, p. 219.

17. Archivo del Ministerio de Asuntos Exteriores y Cooperación (Madrid) - "Archivo de Barcelona" - RE.137.

18. Del peso de Léger y su influencia sobre Blum ya se hizo eco Tuñón de Lara hace muchos años. Véase Manuel Tuñón de Lara, «Todavía la no intervención! (Julio-Agosto, 1936)», Historia Contemporánea, $\mathrm{n}^{\circ}$ 5, 1991, pp. 178-180. 
guerra destinado a la República a través de la frontera, sino que trató incluso de obstaculizar la ayuda soviética llegada por vía marítima ${ }^{19}$.

En el marco de una reunión del Comité Permanente de la Defensa Nacional celebrada el 15 de marzo de 1938, Blum y Paul-Boncour propusieron la posibilidad de dar un ultimátum a Franco, así como de llevar a cabo una hipotética operación sobre las Baleares o el Marruecos espańol. Los militares lo vieron inviable. Léger lo calificó de casus belli contra Italia y Alemania. Ello frenó toda posibilidad de cambio decisivo en la política exterior francesa. La única gran medida práctica favorable a la República durante este segundo Gobierno Blum fue la intensificación de apoyo material al gobierno español. No obstante, no era sino una continuidad de los pasos dados ya por el Gobierno Chautemps. La diferencia estribó en que Blum estipuló la apertura fronteriza en base a decretos reservados que eran de obligado cumplimiento para la administración. En resumen, ello implicaba una apertura de la frontera sin límite alguno. Es decir, en la práctica suponía poner fin a la no intervención. En cambio, la apertura de Chautemps no se hizo de forma oficial y, por lo tanto, carecía de base jurídica. No era un detalle menor. Ese paso, adoptado el 17 de marzo, posibilitó que la República aguantase en pie todavía un año más. Sin embargo, el segundo Gobierno Blum apenas duró un mes. Con ello caía también el Front Populaire. Pese a que Paul-Boncour albergó esperanzas de continuar como ministro, la diferencia de criterios esenciales entre él y el nuevo primer ministro, Édouard Daladier, lo hizo imposible. Su sustitución por Georges Bonnet representó un nuevo revés de enorme importancia para la República.

\section{No intervención y APPEASEMENT: El Gobierno Daladier, PAREJA PERFECTA DE ChAMBERLAin}

Como ya se ha señalado, con la salida de Eden y su sustitución por lord Halifax, el camino quedó expedito para Chamberlain dentro del gabinete. Pronto se le sumaría otra pareja de baile perfecta desde París. Sin embargo, antes de ello se produjo un paréntesis que conllevó el fin de la coalición gubernamental del Front Populaire. A mediados de marzo, Blum volvió a ocupar el puesto de primer ministro. Su gobierno no llegó a durar ni un mes, siendo sustituido por otro encabezado por quien sería la última bête noire de los republicanos españoles: Édouard Daladier. Del Quai d'Orsay pasó a ocuparse otro personaje de similar hostilidad hacia los demócratas del país vecino, como lo fue Georges Bonnet.

Con el binomio Daladier-Bonnet, la hostilidad de Francia hacia la República vecina alcanzó su más alto nivel tanto en el ámbito diplomático -con el papel jugado por el ministro ante la Sociedad de Naciones, como se verá a

19. Ángel Viñas, El honor de la República: Entre el acoso fascista, la hostilidad británica y la politica de Stalin, Barcelona, Crítica, 2008, p. 324. 
continuación- como en el técnico -impidiento el paso fronterizo del material enviado por la Unión Soviética a la República a través de territorio francés-. Los envíos de Moscú hacia la República pasaron a reactivarse una vez que Stalin consideró que Japón no representaba tanto peligro como había temido. Sin embargo, para entonces había cambiado la titularidad del gobierno en París. Daladier no representó sino la última de las desgracias internacionales para los republicanos españoles. Tal factor fue clave, pues puso fin a la Batalla del Ebro, toda vez que la República pasó a carecer del armamento indispensable para el combate, pues a partir del establecimiento de un plan de control por parte del Comité de No Intervención -con el teórico fin de evitar cualquier injerencia internacional en el conflicto español-y el hundimiento de un buque soviético (el Komsomol) en aguas mediterráneas a mediados de diciembre de 1936, el transporte de armamento destinado a la República se llevaba a cabo a través de Francia (los envíos se realizaban por vía marítima entre los puertos de Murmansk y Burdeos).

Pero no contento el Gobierno Daladier con dificultar la supervivencia de la República en el campo de batalla, optó también por un cuestionable -y, de hecho, cuestionado- papel de obstrucción en la arena diplomática. La reunión del Consejo de la Sociedad de Naciones celebrado en mayo de 1938 fue precedido de un encuentro privado en Londres entre Chamberlain, Halifax, Daladier y Bonnet, en el cual se definieron las líneas a seguir en el terreno internacional: buscar el apaciguamiento de Hitler y Mussolini mediante un encuentro personal con ambos. Se trataba del inicio del camino que condujo a los Acuerdos de Múnich meses más tarde. En relación a España, Chamberlain aseguró que la victoria de Franco era cuestión de días o semanas, por lo que era conveniente evitar que el gobierno español complicase las cosas en la inmediata reunión de la Sociedad de Naciones. Es decir, lo que ya venían haciendo ambos países desde el inicio de la contienda, pero ahora de forma revigorizada. A ello se dispusieron franceses y británicos en Ginebra.

Las primeras palabras de Bonnet en el Palais des Nations fueron más cálidas que las de un beligerante Halifax. El ministro francés afirmó haber escuchado "con gran emoción el noble discurso" con el que Álvarez del Vayo había reflejado «la angustia de la España desgarrada», añadiendo: «¿Cómo es posible permanecer insensible a la evocación de los sufrimientos de este país?». Detrás de esas palabras estaba el incremento de la presión por parte de la opinión pública gala, lo cual quedó reflejado en algunas de referencias implícitas entre sus palabras. Acto seguido, exculpó la responsabilidad de su país en el drama español, y no sólo reafirmó la política de no intervención como la única que podía aspirar a lograr una paz europea, sino que se permitió añadir que era también la que más convenía a la propia España.

En vista de que Alemania e Italia seguirían ayudando al bando franquista, en tanto que ni Gran Bretaña ni Francia parecían dispuestas a tratar de impedir tal intervención, se preguntó Álvarez del Vayo en voz alta: «¿En nombre de qué justicia se pueden permitir ambos gobiernos continuar privando al gobierno legítimo de España de aquellos medios a los que le da derecho 
la ley internacional?». Añadió que si dicha pregunta no tenía una respuesta satisfactoria, el pueblo español vería en la conducta de ambas democracias algo monstruoso, a la par que explicable únicamente desde un deliberado propósito de Londres y París de «estrangular su lucha de independencia y entregarle atado de pies y manos a los invasores». Terminó el ministro español sometiendo al Consejo un proyecto de resolución por el cual se invitaría a considerar el final de la política de no intervención, tal y como se había estipulado en el proyecto de resolución presentado ante la Asamblea de la propia Sociedad de Naciones el 2 de septiembre anterior ${ }^{20}$. Halifax zanjó la cuestión con una frase memorable: «La lucha que se sigue en España es una cuestión demasiado grave como para que pueda ser objeto de polémica». Bonnet, por su parte, justificó la no intervención como medio para garantizar la independencia del pueblo español y su posibilidad de determinar su destino por sí mismo, al abrigo de influencias extranjeras. Por ello reiteró la fidelidad de su gobierno a tal política.

Gran Bretańa, Francia, Polonia y Rumanía fueron los únicos países que votaron en contra de la resolución propuesta por el gobierno español en Ginebra. Con ello se evidenciaba la absoluta animadversión franco-británica hacia la causa democrática española. En la votación hubo nueve abstenciones, número poco habitual que revelaba simpatía hacia la causa republicana, pero no hasta el punto de estar dispuestos a romper la concordia ginebrina en defensa de la democracia española. Ante la falta de unanimidad, la propuesta española quedó rechazada. André Simone (pseudónimo de Otto Katz, agente de la Internacional Comunista), presente en el acto, escribió que los respectivos votos en contra por parte de Halifax y Bonnet «cayeron en el silencio muerto como rápidas bofetadas». Una periodista suiza no pudo evitar romper a llorar. Álvarez del Vayo abandonó la sala "pálido de muerte, pero severamente erguido». Bonnet, a su regreso al Hôtel des Bergues, fue increpado en el lobby, mientras trataba de justificar ante los periodistas su actuación, alegando que no podía haber hecho otra cosa, si bien matizando todavía que no se dejaría que España cayese en manos de Hitler y Mussolini. Gritos como «has matado a España!» se dirigieron al ministro, quien, pálido, puso rápidamente rumbo al interior del hotel. ${ }^{21}$ Para colmo, la mencionada declaración de Bonnet para librarse del acoso periodístico fue utilizada oportunamente por Mussolini para justificar un agresivo discurso propio en Génova, lo que no hizo sino complicar más las cosas, tal y como lamentó Halifax a su regreso a Londres ${ }^{22}$.

En la sesión conjunta de Asamblea y Consejo de la Sociedad de Naciones celebrada en el otoño de aquel año 1938, Negrín sorprendió al anunciar la retirada de suelo español de aquellos combatientes extranjeros que integraban las filas republicanas. La salida de las Brigadas Internacionales no fue sino

20. Archivo del Ministerio de Asuntos Exteriores y Cooperación (Madrid) - "Archivo de Barcelona" - RE. 107.

21. André Simone, J'Accuse! The Men Who Betrayed France, Sydney, George G. Harrap \& Co., 1941, pp. 174-176.

22. The National Archives (London) - CAB/23/93 - 296. 
un último intento, a la desesperada, de tratar de restar todo componente internacional a la contienda por parte del Gobierno de la República, en aras de lograr idéntica medida en el campo franquista. Ello no tendría lugar. En cuanto a las tareas de repatriación de dichos combatientes, la delegación francesa en Ginebra abogaba por implicar a la Sociedad de Naciones en la tarea, en lugar de dejarla exclusivamente en manos del Comité de No Intervención. Se alegó que, aunque sólo fuese por el bien del prestigio de la propia Sociedad de Naciones, ésta no podía eludir tomar acción cuando se le pedían simplemente labores de observación. El rol del organismo multilateral sería análogo al de la comisión encargada de investigar los bombardeos aéreos, cuya sede se habaía fijado en Toulouse. De tal modo, «la actitud de la Sociedad de Naciones parecería menos negativa». La delegación británica aceptó en principio la propuesta -elaborada por la delegación gala sin consultar al Quai d'Orsay-, y la sometió a aprobación en el Foreign Office, donde sería ratificada ${ }^{23}$.

El gobierno español ofrecía a las democracias occidentales una nueva oportunidad al abogar por la retirada del conflicto de todos los combatientes extranjeros, pero en ningún caso cedería como lo había hecho el Gobierno Beneš en Checoslovaquia tras los Acuerdos de Múnich -que implicaron la cesión de los Sudetes a Alemania-. Sin embargo, Londres y París continuaron presionando de cara a establecer en Espańa una paz a cualquier precio. Imposible llegar a puntos en común. La firmeza española quedó bien reflejada con motivo de una visita a Barcelona por aquellas fechas por parte del ex ministro francés Vincent Auriol, quien había sido uno de los más firmes defensores de la causa republicana en Francia desde el inicio de la contienda. Álvarez del Vayo le dejó claro que si el embajador de su país se dirigía al Gobierno de la República del mismo modo en que los representantes de Gran Bretaña y Francia lo habían hecho con el presidente Beneš en Praga, la respuesta sería la retirada de sus pasaportes ${ }^{24}$.

El 21 de septiembre, Litvinov afirmó ante la Asamblea que la Unión Soviética había notificado a Francia y a Checoslovaquia que Moscú cumpliría con los compromisos establecidos con el gobierno español. Francia permaneció impasible. Una semana más tarde, Álvarez del Vayo y el embajador Marcelino Pascua visitaron el Quai d'Orsay y constataron que los Acuerdos de Múnich habían producido cierta vergüenza entre los propios miembros del gobierno francés. Una sensación bien diferente a la emoción de Chamberlain al mostrar, en la escalerilla misma del avión que le llevó de vuelta a Londres, el papel con su firma al lado de la de Hitler, documento que en teoría garantizaría que los países que ambos dirigían no terminasen enfrentados en guerra. En París las cosas se veían de forma muy diferente. No era para menos. El mismo Daladier pasó a estimar que se hallaba en un callejón sin salida, tanto para su país como para su posición personal al frente del gabinete. Por el contrario, Bonnet se mostró como un firme defensor de la línea seguida hasta entonces,

23. Ministère des Affaires Étrangères - AD - SDN (La Courneuve, Paris) - 2053.

24. Julio Álvarez del Vayo, Freedom's Battle, New York, Hill and Wang, 1971, pp. 252-254. 
e incluso partidario de acentuarla todavía más, con la nada oculta intención de ponerse él mismo al frente del gobierno ${ }^{25}$. El líder de la diplomacia gala no sólo se mostró plenamente satisfecho con lo acontecido en Múnich, sino que incluso se permitió recomendar un Múnich particular para la cuestión española. Como es lógico, la indignación de los dos representantes españoles desbordó las paredes del ministerio situado a orillas del Sena.

A comienzos de 1939 tuvo lugar una nueva reunión del Consejo de la Sociedad de Naciones, último acto del organismo en que Espańa tendría presencia. Para entonces ya habían terminado las vidas tanto de la República como de la propia Sociedad de Naciones. Álvarez del Vayo decidió abstenerse de cuidar el tono diplomático que hasta entonces había tratado de conservar: «Sí, señores. Gravemente herido, abandonado y traicionado, el pueblo español proseguirá la resistencia. No ha podido restablecerse la paz en la justicia y no nos queda sino luchar hasta la muerte. Pero llegará un día en que os acordaréis de nuestras advertencias y en que os daréis cuenta de que España era el primer campo de batalla de la Segunda Guerra Mundial, que se acerca inexorablemente». Halifax, quien días atrás había acudido a Roma junto a Chamberlain para reunirse con Mussolini, abandonó bruscamente la sesión. Bonnet se mantuvo en su asiento, si bien sonriendo sarcásticamente ${ }^{26}$.

Cuando años más tarde Bonnet publicó sus diferentes libros de memorias afirmó que, a su llegada al Quai d'Orsay, la Sociedad de Naciones estaba muerta -apreciación correcta-, y se lamentaba de que sirviese para asuntos como el tráfico de opio, la supresión de barreras aduaneras o la trata de blancas, pero no para cumplir con su razón de ser, que no era otra que mantener la paz en el mundo. Se quejó asimismo de la necesidad de unanimidad en las resoluciones ginebrinas y que, aun lograda ésta, no existían fuerzas armadas propias del organismo para asegurar la ejecución de los acuerdos alcanzados. Olvidaba Bonnet que, en cualquier caso, era responsabilidad de los Estados que nutrían la existencia de la Sociedad de Naciones el asegurar que se llevasen a cabo las acciones estipuladas en el Pacto. Y, por supuesto, con Francia en primera línea de responsabilidades, en virtud de su propio peso en el continente europeo. Bonnet escribió largo y tendido acerca del organismo ginebrino dentro de su experiencia al frente del Quai d'Orsay y, sin embargo, la Guerra de España apenas es merecedora de salpicadas referencias, como cuando menciona de pasada y en medio de un contexto analítico de las relaciones tripartitas Francia-Gran Bretańa-Italia, el asunto de la retirada de los combatientes italianos enviados por Mussolini al campo franquista ${ }^{27}$. Tampoco faltan nada menos que tres recordatorios de que el gobierno británico había enviado un representante oficioso a Burgos. Se trata de un vago mecanismo exculpatorio

25. Archivo de la Fundación Pablo Iglesias (Alcalá de Henares, Madrid) - AJAV - 945 - 12: Correspondencia delegación de España ante la SDN y legación en Praga - 115.

26. Jean-François Berdah, La democracia asesinada: La República española y las grandes potencias, 1931-1939, Barcelona, Crítica, 2002, p. 413.

27. Georges Bonnet, Défense de la paix : De Washington au Quai d'Orsay, Genève, Constant Bourquin, 1046, p. 89 y pp. 145-147. 
y autojustificativo. De otro modo no resulta comprensible que su olvido para con el caso español vaya acompañado de insistentes referencias a un punto tan concreto, en el que debió de haberse amparado con frecuencia en sus argumentaciones de la época, y el cual quedó retenido en su subconsciente como una obsesiva clave justificatoria. Pero no debe extrañar que Bonnet corriese un tupido velo en torno a la cuestión española, toda vez que publicó sus escritos tras el fin de la Segunda Guerra Mundial, fecha en la cual reflejar su verdadero papel en relación a Espańa le hubiese deparado un nada glorioso papel histórico, así como una reinserción un tanto menos plácida en su propio país, marcado a fuego por la vergüenza de Vichy y enfrascado en una implacable condena a colaboracionistas. Ante tal panorama, resulta comprensible y lógico que Bonnet no reflejase su mayor simpatía hacia Franco que hacia Negrín o Âlvarez del Vayo, con quien protagonizó incidentes no muy dignos en Ginebra. De todos modos, Bonnet no podría librarse del oprobio de la gran mayoría de sus compatriotas ${ }^{28}$.

En la fase final del encuentro ginebrino, dentro de la comisión en la cual fue abordada la cuestión española, tanto Halifax como Bonnet fueron reemplazados por Richard Butler y Émile Charvériat, respectivamente. Se trató de un último desplante a la democracia española por parte franco-británica, para cerrar una suerte que ambos países habían contribuido a determinar más que ningún otro desde casi tres años antes.

\section{UN EPÍLOGO NADA DECOROSO:}

\section{El SEGUNDO ABANDONO DE LA DEMOCRACIA ESPAÑOLA}

El abandono franco-británico a la democracia española tuvo una segunda parte. Cuando, en 1945, Mussolini y Hitler cayeron derrotados en el campo de batalla de la Segunda Guerra Mundial, el general Franco, en solitario, ya no representaba un peligro. Así lo entendieron los británicos, con Winston Churchill a la cabeza, y Francia no había salido de la contienda precisamente con capacidad de decisión alguna, toda vez que su liberación de la ocupación alemana había sido posible gracias a las acciones de las principales fuerzas aliadas (fundamentalmente norteamericanas en el caso concreto francés), así como por una Resistencia en el interior del país a la cabeza de la cual estuvieron miles de republicanos perdedores en España, pero exiliados en el país galo, combatientes por la liberación de Europa y virtuales compañeros de victoria de los Aliados. De nada sirvió que los primeros hombres en liberar París del nazismo fuesen los españoles de la División Leclerc. Pero el pragmatismo se

28. Ya en 1941, Frank Owen no tuvo la menor piedad al escribir que el gobierno de capitulacionistas de Vichy estaba «muy próximo al gobierno de los sueños de Bonnet», apostillando: «La única partícula de realidad desagradable sobre el mismo, para Bonnet, era que no se le había incluido en él en un buen puesto». André Simone, op. cit., p. 7 (del prólogo de Frank Owen). 
impuso a cualquier virtual atisbo de justicia histórica. Bastaba con obviar que Franco había alcanzado al poder con la ayuda de los otros dos dictadores derrotados. Habían comenzando nuevos tiempos marcados al compás de la Guerra Fría. Nuevamente, las democracias occidentales abandonaban a su homóloga española en una posposición sine die.

Los objetivos tácticos y estratégicos que conducen la acción política (siempre unidos a unos componentes ideológicos) se impusieron, como no cabe extrañar, a la más mínima consideración de justicia histórica. El pragmatismo se impuso, una vez más, al idealismo. La Sociedad de Naciones había muerto, precisamente a causa de la impunidad que resultó de las agresiones cometidas durante la década de los años treinta por parte de los tres países que constituirían el Eje. Si el organismo ginebrino volvió a nacer reencarnado en la Organización de las Naciones Unidas, a la democracia española todavía le faltarían tres largas décadas por delante para empezar a ver de nuevo la luz. Lo que ocurrió entre medias sobrepasa el objeto del presente artículo. Pero si Espańa fue la gran perjudicada, cabe señalar que también Francia conserva no pocas cicatrices que recuerdan el precio de una política exterior errada -tanto desde el punto de vista ético como en cuanto a los mismos intereses nacionales-. El miedo y el egoísmo de los dirigentes franceses de la época contribuyeron decisivamente a no frenar la escalada de una nueva guerra mundial, y conllevaron no sólo el trauma de Vichy, sino la consagración de aquella décadence de la que habló el historiador Jean-Baptiste Duroselle. 